\title{
Transplantation Immunology
}

National Cancer Institute

\section{Source}

National Cancer Institute. Transplantation Immunology. NCI Thesaurus. Code C17215.

Studies that pertain to the immunological barriers to transplanting organs and tissues between individuals of different species (xenotransplantation) and between individuals of the same species (allotransplantation). 